\title{
Multidimensional factor structure of unusual experiences: new measures of positive schizotypy
}

\author{
Maha Charabi ${ }^{1}$, Eugenia Kravariti ${ }^{2}$, Michael W. Eysenck ${ }^{1}$ \& Elias Tsakanikos ${ }^{1}$ \\ ${ }^{1}$ Department of Psychology, University of Roehampton, London, UK and ${ }^{2}$ Department of \\ Psychosis Studies, Institute of Psychiatry, Psychology \& Neuroscience, London, UK
}

Short title: Is Positive Schizotypy Multi-Dimensional?

Accepted for publication in Personality and Individual Differences, April (2019). 


\title{
Author's Pre-print
}

\begin{abstract}
Positive schizotypy has been employed as a unitary construct in previous experimental research despite the phenomenological heterogeneity of the schizotypal experiences that it describes. In the present paper, we report two psychometric studies on the Unusual Experiences (UE) scale, a widely employed measure of positive schizotypy from the Oxford -Liverpool Inventory for Feeling and Experiences (O-LIFE; Mason, Claridge, \& Jackson, 1995). Study $1(\mathrm{~N}=829)$ explored the factor structure of UE and model fit was assessed using Confirmatory Factor Analysis (CFA). Study $2(\mathrm{~N}=108)$ evaluated the validity of the factors by employing well-established measures of schizotypy related to positive symptomatology. The results supported a theoretically meaningful 3-factor solution: UE1 Unusual perceptions, UE2 Unusual salience/reality monitoring, and UE3 Unusual beliefs. The new subscales had adequate psychometric properties. We propose that the new subscales have the potential of improving research cohesion, motivating further research and enhancing understanding of experimental correlates of positive schizotypy.
\end{abstract}

Keywords: delusions; hallucinations; psychosis-like symptoms; positive symptoms of schizophrenia; positive schizotypy; 


\section{Author's Pre-print}

The Unusual Experiences (UE) scale of the Oxford -Liverpool Inventory for Feeling and Experiences (O-LIFE; Mason, Claridge, \& Jackson, 1995) is a well-validated, widely employed measure of positive schizotypy. Positive schizotypy describes unusual experiences and irregular thought processes akin to those observed in positive symptoms of schizophrenia, such as hallucinations, delusional ideation and perceptual aberrations (Frith, 2008; D'haenen, den Boer, \& Willner, 2002; Brown \& Cohen, 2010; Hoshi, Scoales, Mason, \& Kamboj, 2011; Couture, Penn, \& Roberts, 2006; Costafreda et al., 2008; Avons, Nunn, Chan, \& Armstrong, 2003). These schizophrenia-like traits are often seen as a "diluted" version of the disorder (Handest \& Parnast, 2002). UE consists of items from factor analytic studies on older scales that have been designed to assess a range of schizophrenia-like traits (e.g. Chapman, Chapman, \& Raulin, 1978; Launay \& Slade, 1981; Eckblad \& Chapman, 1983; Claridge \& Broks, 1984; Bentall, Claridge, \& Slade, 1989) assessing mainly atypical beliefs and unusual experiences, such as "When in the dark do you often see shapes and forms even though there is nothing there?" and "Are your thoughts sometimes so strong that you can almost hear them?" or "Have you ever felt that you have special, almost magical powers"?

In longitudinal studies, positive schizotypy appears to predict clinical psychopathology in non-clinical populations, as well as clinical outcomes in patient populations (Gooding, Kathleen \& Matts 2007; Gooding, Tallent, \& Matts, 2005; Werbeloff, Drukker, Dohrenwend, Levav, Yoffe, van Os et al., 2012; Kaymaz, Drukker, Lieb, Wittchen, Webeloff, Weiser et al., 2012; Dominguez, Wichers, Lieb, Wittchen, \& van Os, 2011; in Fonseca-Pedrero, Paino, Ortuno-Sierra, Leoms-Giraldez, \& Muniz, 2014). Elevated schizotypy traits have also been observed in those with biological-risk (Calkins, Curtis, Grove, \& Iacono, 2004; Park, Kirk, \& 


\section{Author's Pre-print}

Waldie, 2015; Fisher et al., 2004; Nettle, 2006) as well as in patient groups (e.g. SchultzeLutter, Fluckiger, Michel, \& Hubl, 2018), while neurocognitive deficits overlap with those found in schizophrenia (Ettinger et al., 2014).

Although positive schizotypy has apparent phenotypic similarities with schizophrenia spectrum disorders, high scores on measures positive schizotypy are not necessarily pathological. A number of studies have found associations between positive schizotypy and measures of creativity (Batey \& Furnham, 2008), amongst visual artists (Burch, Pavelis, Hemsley \& Corr, 2006; Rawlings \& Locarnini, 2008), musicians (Rawlings \& Locarnini, 2008) and comedians (Ando, Claridge, \& Clark, 2014). Many authors have explained creativity as a broader generation of ideas or different patterns of thinking about semantic relatedness, such as those suggested by an inclination towards making 'unusual word associations' (Rawlings \& Locarnini, 2008).

Experimental researchers have employed various paradigms to investigate irregular information processing in positive symptoms schizophrenia and traits of positive schizotypy. These experimental paradigms tend to fall into three broad categories: Attentional, such as incidental learning (e.g. Burch, Hemsley, Corr, \& Gwyer, 2006), filtering irrelevant stimuli (e.g. Gray, Fernandez, Williams, Ruddle, \& Snowden, 2002; Granger, Prados, \& Young, 2012), latent inhibition (e.g. Granger, Prados \& Young, 2012; Shrira \& Tsakanikos, 2009), and Kamin blocking (Al-Uzri, Watson \& Reveley, 2003), prepulse inhibition (PPI) (Kumari, Soni, Mathew, \& Sharma, 2000), and salience of unattended stimuli (Burch, Hemsley, Corr, \& Gwyer, 2006); Reality monitoring, where participants are tested on their the ability to distinguish between their internal mental phenomena (such as thoughts, memories and mental images) from externally generated events (e.g. Allen, Johns, Broome, Vythelingum, \& McGuire, 2004; Costafreda, Brebion, Allen, McGuire, \& Fu, 2008); and Cognitive biases 


\section{Author's Pre-print}

such as jumping to conclusions on the basis of little information (Garety, Hemsley, \& Wessely, 1991), "seeing” non-existing events (e.g. Grant et al., 2014; Tsakanikos \& Reed, 2005b; 2005c; Tsakanikos, 2006), illogical reasoning, observed in those experiencing delusions as well as in non-clinical schizotypal populations (e.g. Huq, Garety, \& Hemsley, 1988; Garety, Hemsley, \& Wessely, 1991; Woodward, Moritz, Cuttler, \& Whitman, 2006; Buchy, Woodward, \& Liotti, 2007; Balzan, Delfabbro, Galletly, \& Woodward, 2012) and confirmation bias paradigms (e.g. Woodward et al., 2006; Buchy et al., 2007; Balzan et al., 2012).

While many previous studies have used UE to assess positive schizotypy as a unidimentional measure, other studies have instead opted for symptom-specific scales. For example, when assessing studies in relation to vividness or perceptual salience of stimuli, the Perceptual Aberration Scale (PAS; Chapman, Chapman, \& Raulin, 1978) or the Abberant Salience Inventory (ASI; Cicero, Kerns, \& McCarthy, 2010) has often been used (Stefanis et al., 2006; Compton et al., 2009; Fonseca-Pedrero et al., 2010; Fonseca-Pedrero et al., 2014). For hallucination or hallucinatory-related studies, the Launay-Slade Hallucination Scale (Launay \& Slade, 1981) or the revised version (Launay \& Slade, 1981; Bentall \& Slade, 1985a), has been employed (e.g. Levitan et al., 1996; Levine, 2004; Van Wout et al., 2004; Preti et al., 2007; Badcock et al., 2008; Chhabra et al., 2011; Vellante et al., 2012; Preti et al., 2014). When considering unusual beliefs, the Magical Ideation Scale (Eckblad \& Chapman, 1983) has often been employed, for example, to investigate delusional thinking or paranormal ideology (e.g. Yeon Jung et al., 2008; Fonseca-Pedrero et al., 2010; Fonseca-Pedrero et al., 2014).

Despite the clear benefit of symptom-specific measures this can potentially attenuate cohesion of schizotypy research by making comparisons across studies more difficult 


\section{Author's Pre-print}

(Ditman \& Kuperberg, 2005). Assessing positive schizotypy as a unitary construct can be useful in identifying a cluster of underlying trait measures, which may correspond to an endophenotype of psychosis-proneness. Unitary measures of positive schizotypy, however, could be further refined to give researchers more detailed information about specific aspects of schizotypal phenomenology linked to putative underlying cognitive and perceptual mechanisms and, therefore, to facilitate comparisons with symptom-specific studies.

Although the Unusual Experiences (UE) scale consists of items selected from a range of older symptom-specific scales assessing different aspects of the schizophrenia-like phenomenology (see Mason, Claridge, \& Jackson, 1995) the factorial structure of this scale has never been evaluated. As reviewed earlier, experimental researchers have typically focused on three broad cognitive domains (i.e. selective attention, reality monitoring and cognitive biases) with respect to different measures of positive schizotypy. One previous factor analytic study (Cicero \& Kerns, 2010) on items from various symptom-specific measures of positive symptomatology has revealed a 3-factor structure, supporting the notion that positive schizotypy is a multi-dimensional construct. Consequently, it is conceivable that positive schizotypy, as assessed by UE, could be further reduced to more specific subscales. Therefore, the present study aimed to investigate for the first time the underlying the factor structure of UE in a large sample of participants (Study 1) and examine the psychometric properties of newly derived UE sub-scales (Study 2) by employing a number of established symptom-specific measures of positive symptomatology.

\section{Study 1}

Methods

Participants 


\section{Author's Pre-print}

Nine-hundred-and-six participants completed the Unusual Experiences scale (UE) of the Oxford -Liverpool Inventory for Feeling and Experiences (O-LIFE; Mason, Claridge, \& Jackson, 1995). Participants were aged between 18 and 68 (61\% female, 36\% male and 3\% did not specify). The UE data were taken from a large dataset $(\mathrm{N}=756)$ collated from previous studies by Tsakanikos and colleagues (Tsakanikos \& Claridge, 2005; Tsakanikos \& Reed, 2005a; 2005b; 2005c; Tsakanikos, 2006; Shrira \& Tsakanikos, 2009) with the remaining cases consisting of newly collected data.

Analysis

The data of 906 participants were sorted to identify missing cases. Ages in the sample ranged from 16 to 68 with a mean age of 22.15 (s.d = 7.24). Data for participant sex was available for 805 participants (300 males, 505 females). A number of answers were omitted from the sub scale items in the final sample for the CFA was reduced to avoid estimations $(n=829)$ including 2 additional participants that did not have complete UE data. This left complete UE sub-scale data for 829 participants and complete UE total scale data for 827 participants.

The UE items were divided into three thematic sub-scales according on the basis of 1) results from one earlier exploratory factors analysis (Varimax Principal Axis Factoring) from Tsakanikos et al studies $(\mathrm{N}=742)$ that had identified a 3-factor solution 2) the literature on positive symptomatology and inspection of the semantic content of items. This led to the creation of three new sub-scales (see Appendix 1) reflecting different types of experiences: Unusual perceptions (UE1, 9 items), Unusual salience/ reality monitoring (UE2, 8 items) and Unusual beliefs (UE3, 7 items). 6 items were omitted due ambiguity regarding placement of these items within content related theme, as well as examination of the oblique and rotated factor solutions. Parallel Analysis was then used to determine the appropriate number of 


\section{Author's Pre-print}

factors to extract in the model. Eigenvalues were calculated for complete item level data using SPSS Version 24, and the values compared with average eigenvalues computed using an online Parallel Analysis software (Patil, Singh, Mishr, \& Donovan, 2008). Eigenvalues were calculated based on both 24 and 30 items being present, in an 829-person sample. These were calculated at $95^{\text {th }}$ percentile of 100 randomly generated correlation matrices. Observed eigenvalues for the first four components were 5.01, 1.60, 1.45 and 1.17 , respectively. The eigenvalue of the first three components was greater than that required according to Parallel Analysis, but this was not the case for the fourth component $(1.32,1.27,1.23,1.20)$. This suggested that 3 factors were present in the data. Confirmatory Factor Analysis (CFA) was then conducted using AMOS, in order to assess the fit of this three-factor model. In addition, a test of invariance was used to assess whether there were gender differences between the constrained and non-constrained model.

\section{Results}

The CFA demonstrated that all items were significantly loaded onto the corresponding factors (UE1 from .39 to .61, UE2 from .38 to .59, UE3 from .35 to .54). Factors were predicted to be independent in etiology but were also expected to correlate to each other. The factors did significantly correlate to each other (UE1 - UE2 r=.65, UE1 - UE3 r=.68, UE2 UE3 $r=.69)$. The overall fit for the model was significant $\chi^{2}(249)=623.64, p<.001$ suggesting a lack of fit, however given the large sample size that increases statistical significance in CFA, other measures were considered to determine the suitability of the model. Consideration of these additional measures suggested that the model was acceptable parameters for most measures, but not those of CFI and TLI $(\mathrm{CFI}=.88, \mathrm{AGFI}=.93, \mathrm{RMR}=$ $.01, \mathrm{SRMR}=.44, \mathrm{GFI}=.94, \mathrm{TLI}=.87, \mathrm{RMSEA}=.03, \mathrm{PCLOSE}=1.00)$. 


\section{Figure 1 about here}

Inspection of the modification indices suggested that 2 items within each factor were highly correlated to each other $($ M.I > .20). There were none of these between factors. On inspection of these items, they did appear to directly assess similar content. In the UE1 subscale, two covarying items were "Have you occasionally felt as though your body did not exist?" and "Have you felt as though your head or limbs were somehow not your own?", both of which appeared to assess lack of a sensation of body ownership. In the UE2 sub-scale, covarying items were "Does it often happen that nearly every thought immediately and automatically suggests an enormous number of ideas?" and "Do ideas and insights sometimes come to you so fast that you cannot express them all?", both appearing to assess overwhelm. The UE3 sub-scale also had two items covarying that seemed to both assess a very similar type of magical experience "Do you think you could learn to read other's minds if you wanted to?" and "Can some people make you aware of them just by thinking about you?". A revised model allowed these 6 items ( 2 within each factor) to covary, leading to a better overall fit, $\chi^{2}(246)=504.34, p<.001$. Although the chi-square was still significant, other indicators suggested that the model provided an adequate fit $(\mathrm{CFI}=.92, \mathrm{AGFI}=.94, \mathrm{RMR}=$ $.01, \mathrm{SRMR}=.04, \mathrm{GFI}=.95, \mathrm{TLI}=.91, \mathrm{RMSEA}=.04$, PCLOSE $=1.00)$. Chi-square was calculated between the original constrained model, and the non-constrained model that allowed these items to covary, and this difference was found to be significant $\chi^{2}(3)=$ $119.26, \mathrm{p}<.001$. This suggested that the models were significantly different, with the non- 


\section{Author's Pre-print}

constrained model provided better fit. Further analyses confirmed that UE1 explained $11.50 \%$ of the variance, UE2 explained $10.33 \%$ of the variance and UE3 explained $9.35 \%$ of the variance within the dataset.

\section{Figure 2 about here}

A metric invariance test was conducted with two groups (males and females) to determine if there were gender differences at the model level. A chi-square test assessed the difference between the fully constrained $\left(\chi^{2}(513)=837, \mathrm{p}<.0001\right)$ and the non-constrained models $\left(\chi^{2}(492)=813.9, \mathrm{p}<.0001\right)$ and found no group difference, suggesting the model fit similarly for males and females, $\chi^{2}(21)=23.1, \mathrm{p}=.339$

\section{Table 1 about here}

Correlations (Table 1) were observed between age and the total Unusual Experiences score out of 30 , in addition to correlations between age and the three thematic sub-scales. There was a significant but weak negative correlation between age and the total UE scores $(r=-$ $.084, \mathrm{p}=.017,2$-tailed $)$ as well as the UE2 $(\mathrm{r}=-.11, \mathrm{p}=.002,2$-tailed $)$, but not the other subscales. There was a marginally significant but weak negative correlation between UE3 and 


\section{Author's Pre-print}

age $(\mathrm{r}=-.07, \mathrm{p}<.1,2$-tailed $)$. The means for males and females appeared to be similar across all measures (Table 2).

\section{Table 2 about here}

Factor labeling

The three highest loading factor items were considered in terms of phenomenology and collective experiences described in each factor for labelling purposes. The highest loading items in Factor 1 were 'Do you ever feel suddenly distracted by distant sounds that you are not normally aware of?', 'Have you felt as though your head or limbs were somehow not your own?' and 'Is your hearing sometimes so sensitive that ordinary sounds become uncomfortable?' respectively. On consideration of these experiences, it was deemed that this factor primarily reflects unusual perceptions. For Factor 2, the highest loading items were 'Do your thoughts sometimes seem as real as actual events in your life?', 'Are your thoughts sometimes so strong that you can almost hear them?' and 'Are the sounds you hear in your daydreams usually clear and distinct?' respectively. This factor appeared to primarily reflect unusual salience of subjective /internal events as well as reality monitoring (i.e. distinction between internal processes and actual events). For the third factor, the highest loadings were 'Do you think that you could learn to read other's minds if you wanted to?', 'Can some people make you aware of them just by thinking about you?' respectively, in addition to two others that were equally loaded to the factor 'Have you ever felt that you have special, almost magical powers?' and 'Do you sometimes feel that your accidents are caused by mysterious 


\section{Author's Pre-print}

forces?'. All items clearly related to unusual thinking. Overall, factor labeling and interpretation was in line with the type of experiences contained in each factor and with the phenomenology of positive symptomatology.

\section{Study 2}

Methodology

Design

The present study explored potential associations between the new UE subscales and already established symptom-specific measures of positive schizotypy in order to evaluate the psychometric validity of the new scales.

Participants

The data of 108 student participants was collected ( 27 males, 81 females) from Roehampton University and Goldsmiths University. They were aged between 18 and 51, with a mean age of 22.84 .

Measures

Unusual Experiences (UE; Mason, Claridge, \& Jackson, 1995; a = .88, 30 items). The subscale for factors identified in Study 1 were also considered separately. These were i) UE1 


\section{Author's Pre-print}

assessing unusual perceptions $(\mathrm{a}=.69,9$ items) ii) UE2 assessing unusual reality monitoring $(\mathrm{a}=.77,8$ items $)$ and iii) UE3, thought to be assessing unusual thinking ( $\mathrm{a}=.65,7$ items).

Launay-Slade Hallucination Scale (LSHS; Launay \& Slade, 1981; a = .80, 12 items focuses on auditory and visual hallucination-based experiences. A large part (12 items) of the LSHS has a focus on hallucinatory experiences (i.e. seeing events in their absence) that are mostly of an auditory focus ( 7 items) with some items relating to the reality of thoughts (4 items) and one remaining item focusing on visual hallucination. The questionnaire is scored on a scale from 0 to 4 , where 0 is scored for 'certainly does not apply to me' and 4 is 'certainly applies to me' indicating the level of agreement with the questionnaire item. The questionnaire is positively scored.

Magical Ideation (MI; Eckblad \& Chapman, 1983; a = .74, 30 items). The scale items scored with true / false responses were concerned with magical thinking and unusual beliefs. The questionnaire is positively scored for the majority of items $(23$, true $=1)$ and inversely scored for 7 items (false $=1$ ), indicating presence of magical ideation.

Aberrant Salience Inventory (ASI; Cicero, Kerns \& McCarthy, 2010; a = .88, 29 items). ASI assesses the amount of salience a person places on all (including irrelevant) stimuli. The overall score is thought to reflect aspects of salience such as increased significance of events, sharpened senses, impending understanding, heightened emotions and heightened cognitions. The questionnaire is positively scored, where a yes response indicates presence of increased salience. 


\section{Author's Pre-print}

The eight subscales of the Ways of Coping Scale 'WAYS' revised (Folkman \& Lazarus, 1985)

i) Confrontive coping $(\mathrm{a}=.58,6$ items), ii) Distancing $(\mathrm{a}=.71,6$ items $)$, iii) Self-controlling $(\mathrm{a}=.50,7$ items $), \mathrm{iv})$ Seeking social support $(\mathrm{a}=.71,6$ items), v) Accepting responsibility (a $=.54,4$ items $)$, vi) Escape avoidance $(\mathrm{a}=.71,6$ items $)$, vii $)$ Planful problem solving $(\mathrm{a}=.71$, 6 items) and viii) Positive reappraisal $(\mathrm{a}=.72,7$ items). Participants responded on a 4-point Likert scale $(0=$ does not apply and/or not used; $3=$ used a great deal $)$ to indicate their typical way of coping in a particular stressful encounter.

\section{Results}

The correlations (Table 3) between all the new UE scales were substantial and statistically significant $(\mathrm{p}<.01)$. The UE1 scale correlated mostly with the LSHS, whilst the UE2 scale also correlated mostly with this scale. The UE3 scale correlated mostly with the MIS. The MIS scale was most associated to the overall UE and the UE3 scale. The LSHS was mostly correlated to the UE and the UE2 scale. The ASI scale was also mostly correlated to both total UE and UE2. The UE itself loaded highly onto both the UE1 and UE2 scales and still highly onto the other scales.

Table 3 about here

Correlations between the coping mechanisms, the new UE measures as well as all the other schizotypy scales are presented in Table 4. Comparative inspection of the correlations 


\section{Author's Pre-print}

between the variables reveals that although some coping mechanisms (Self-Controlling, Seeking social support, Accepting responsibility, Escape-Avoidance) were associated with the total UE score, these associations were observed only for UE2 (Self-Controlling, Seeking social support, Accepting responsibility, Escape-Avoidance) or for both UE2 and UE3 (Escape-Avoidance). In one occasion, a particular coping mechanism (Confrontive Coping) was associated only with a new sub-scale (UE2) but not the total UE score.

\section{Table 4 about here}

\section{Discussion}

The results of Study 1 revealed the existence of three factors underlying UE: UE1 -Unusual perceptions, UE2 - Unusual salience/reality monitoring and UE3 - Unusual beliefs. The new factors appear to be psychometrically sound but also theoretically meaningful, reflecting three mains strands of research and distinct aspects of phenomenology in positive symptomatology. Study 2 provided some evidence for the psychometric validity of the new UE sub-scales. Overall, the present findings led support to the notion that UE is not a unidimensional measure and that positive schizotypy can be considered a multi-dimesional construct in line with previous evidence (Cicero \& Kerns, 2010).

Items in factor UE1, 'unusual perceptions', described unusual perceptions of an auditory, visual or sensory nature. One particular item was not as clearly related to the other items in terms of phenomenology - 'Do you ever feel that your thoughts don't belong to you'. This 


\section{Author's Pre-print}

item perhaps relates to an unusual perception of self as 'alien' or perception of personal thoughts not belonging to the self, a sense of depersonalisation. Study 2 provided some evidence of convergent validity, as UE1 was predominantly correlated with the LSHS Launay-Slade Hallucination Scale.

Items in factor UE2, 'Unusual salience/reality monitoring' appeared to reflect a cognitiveperceptual factor with a particular focus on unusual salience of internal events as well as on reality monitoring vulnerability, whereby the items explained the outward impact of thoughts on the environment, being almost physically real. In this scale, 6 of the items detailed what appears as an externalisation of inner thoughts to an expected reality in the outside world. One item 'Does it often happen that nearly every thought immediately and automatically suggests an enormous number of ideas' seems somewhat distinct from the other items, as appears to reflect lack of cognitive control or an increased tendency to quickly generate associations in response an internal event, although it could be argued that both processes could influence reality monitoring. In Study 2, UE2 was predominantly associated with the LSHS Launay-Slade Hallucination scale but also had the highest correlation with Aberrant Salience Inventory (.62) than the other two subscales (.47 and .46$)$.

The third factor, UE3, mostly featured items on magical beliefs and delusional thinking. All items that loaded on this factor related to unusual thinking, including telepathy, 'mysterious forces' or causing things to occur by thinking about them. There was evidence of convergent validity in Study 2 showing that UE2 was primarily correlated with Magical Ideation, a wellestablished scale of delusional thinking. 


\section{Author's Pre-print}

The new UE sub-scales provide schizotypy researchers with the opportunity to re-analyse their experimental data, particularly those who did not find predicted associations with UE as a unidimensional measure. The findings encourage researchers to explore specific aspects of unusual experiences such as reality monitoring, magical beliefs or unusual perceptions as separate constructs, moving towards a multidimensional approach of positive schizotypy which can facilitate comparison across studies and shed light onto previously conflicting evidence.

All new UE sub-scales had adequate internal consistency. Of the three new scales, the UE2 (a $=.77 ; 9$ items) measure of unusual reality monitoring most reliably assessed a single measure, followed by the UE1 $(\mathrm{a}=.69 ; 8$ items) scale assessing unusual perceptions and then the UE3 scale $(\mathrm{a}=.65 ; 7$ items $)$. The relatively modest alpha values can be accounted by the small number of items. It would be therefore desirable for further scale development to add more items with similar content in order to increase the internal consistencies of the new UE sub-scales.

There were a number of limitations in the present study. It is worth noting that the variance in the scores explained by the three-factor solution was relatively low, accounting for a little over 30\%. However, the model fit was statistically sound and the derived factors are theoretically meaningful. A further limitation was the larger proportion of female participants in the sample. This was viewed as problematic due to differences in the onset of psychosis in males and females. However, given the large sample size this was not deemed to be detrimental to the findings. In support of this, a metric test of invariance demonstrated that there was no difference between model fit for males and females. The larger proportion of female participants may have been due to recruiting participants in psychology 


\section{Author's Pre-print}

departments that tend to be of female majority. Furthermore, student samples in general may not be representative of the wider population, and it could be considered that such a sample may also have increased IQ and coping skills that have allowed them to access university education. Therefore, further exploration of the factor structure in the general population would be desirable.

Whilst this research cannot make strong claims about the existence of distinctive phenotypic constructs associated with these subscales, there some obvious benefits of employing a multidimensional approach in positive schizotypy with more specific measures that map onto different symptom-like experiences. We hope that the new UE subscales will refine measurement by providing additional information, improve research cohesion, motivate further research, and therefore, enhance understanding of mechanisms underlying positive schizotypy. 
Author's Pre-print

References

Allen, P. P., Johns, L. C., Fu, C. H., Broome, M. R., Vythelingum, G. N., \& McGuire, P. K. (2004). Misattribution of external speech in patients with hallucinations and delusions.

Schizophrenia Research, 69(2-3), 277-287. http://doi.org/10.1016/j.schres.2003.09.008

Ando, V., Claridge, G., \& Clark, K. (2014). Psychotic traits in comedians. The British Journal of Psychiatry: The Journal of Mental Science, 204, 341-345.

http://doi.org/10.1192/bjp.bp.113.134569

Avons, S. E., Nunn, J. A., Chan, L., \& Armstrong, H. (2003). Executive function assessed by memory updating and random generation in schizotypal individuals. Psychiatry Research, $120(2), 145-154$.

Badcock, J. C., Chhabra, S., Maybery, M. T., \& Paulik, G. (2008). Context binding and hallucination predisposition. Personality and Individual Differences, 45(8), 822-827. http://doi.org/10.1016/j.paid.2008.08.016

Balzan, R., Delfabbro, P., Galletly, C., \& Woodward, T. (2012). Reasoning heuristics across the psychosis continuum: the contribution of hypersalient evidence-hypothesis matches. Cognitive Neuropsychiatry, 17(5), 431-450. http://doi.org/10.1080/13546805.2012.663901 


\section{Author's Pre-print}

Batey, M., \& Furnham, A. (2008). The relationship between measures of creativity and schizotypy. Personality and Individual Differences, 45(8), 816-821.

http://doi.org/10.1016/j.paid.2008.08.014

Bentall, R. P., \& Slade, P. D. (1985). Reliability of a scale measuring disposition towards hallucination: a brief report. Personality and Individual Differences, 6(4), 527-529. http://doi.org/10.1016/0191-8869(85)90151-5

Brown, L. A., \& Cohen, A. S. (2010). Facial emotion recognition in schizotypy: the role of accuracy and social cognitive bias. Journal of the International Neuropsychological Society: JINS, 16(3), 474-483. http://doi.org/10.1017/S135561771000007X

Burch, G. S., Pavelis, C., Hemsley, D. R., \& Corr, P. J. (2006). Schizotypy and creativity in visual artists. British Journal of Psychology, 97(2), 177-90.

http://doi.org/10.1348/000712605X60030

Burch, G. S. J., Hemsley, D. R., Corr, P. J., \& Gwyer, P. (2006). The relationship between incidental learning and multi-dimensional schizotypy as measured by the Oxford-Liverpool Inventory of Feelings and Experiences (O-LIFE). Personality and Individual Differences, 40(2), 385-394. http://doi.org/10.1016/j.paid.2005.07.010

Calkins, M. E., Curtis, C. E., Grove, W. M., \& Iacono, W. G. (2004). Multiple Dimensions of Schizotypy in First Degree Biological Relatives of Schizophrenia Patients. Schizophrenia Bulletin, 30(2), 317-325. 


\section{Author's Pre-print}

Chhabra, S., Badcock, J. C., Maybery, M. T., \& Leung, D. (2011). Context binding and hallucination predisposition: Evidence of intact intentional and automatic integration of external features. Personality and Individual Differences, 50(6), 834-839.

http://doi.org/10.1016/j.paid.2011.01.005

Cicero, D. C., Kerns, J. G., \& McCarthy, D. M. (2010). The Aberrant Salience Inventory: A new measure of psychosis proneness. Psychological Assessment, 22(3), 688-701. http://doi.org/10.1037/a0019913

Cicero, D. \& Kerns, J. G. (2010). Multidimensional Factor Structure of Positive Schizotypy. Journal of Personality Disorders, 24 (3), 327-343.https://doi.org/10.1521/pedi.2010.24.3.327

Claridge, G., \& Broks, P. (1984). Schizotypy and hemisphere function-I. Personality and Individual Differences, 5(6), 633-648. http://doi.org/10.1016/0191-8869(84)90111-9

Compton, M. T., Goulding, S. M., Bakeman, R., \& McClure-Tone, E. B. (2009). Confirmation of a four-factor structure of the Schizotypal Personality Questionnaire among undergraduate students. Schizophrenia Research, 111(1-3), 46-52.

http://doi.org/10.1016/j.schres.2009.02.012

Couture, S. M., Penn, D. L., \& Roberts, D. L. (2006). The functional significance of social cognition in schizophrenia: a review. Schizophrenia Bulletin, 32 Suppl 1, S44-63. http://doi.org/10.1093/schbul/sbl029 


\section{Author's Pre-print}

Costafreda, S. G., Brébion, G., Allen, P., McGuire, P. K., \& Fu, C. H. Y. (2008). Affective modulation of external misattribution bias in source monitoring in schizophrenia.

Psychological Medicine, 38(06). http://doi.org/10.1017/S0033291708003243

D’haenen, H. A. H., Den Boer, J. A., \& Willner, P. (Eds.). (2002). Biological psychiatry. Chichester; Hoboken, N.J: Wiley.

Ditman, T., \& Kuperberg, G. R. (2005). A Source-Monitoring Account of Auditory Verbal Hallucinations in Patients with Schizophrenia: Harvard Review of Psychiatry, 13(5), 280299. http://doi.org/10.1080/10673220500326391

Eckblad, M., \& Chapman, L. J. (1983). Magical ideation as an indicator of schizotypy. Journal of Consulting and Clinical Psychology, 51(2), 215-225. http://doi.org/10.1037//0022-006X.51.2.215

Ettinger, U., Meyhöfer, I., Steffens, M., Wagner, M., \& Koutsouleris, N. (2014). Genetics, Cognition, and Neurobiology of Schizotypal Personality: A Review of the Overlap with Schizophrenia. Frontiers in Psychiatry, 5. http://doi.org/10.3389/fpsyt.2014.00018

Fisher, J. E., Mohanty, A., Herrington, J. D., Koven, N. S., Miller, G. A., \& Heller, W. (2004). Neuropsychological evidence for dimensional schizotypy: Implications for creativity and psychopathology. Journal of Research in Personality, 38(1), 24-31. http://doi.org/10.1016/j.jrp.2003.09.014

Fonseca-Pedrero, E., Paino, M., Lemos-Giráldez, S., Sierra-Baigrie, S., \& Muñiz, J. (2010). Factor Structure and Measurement Invariance of the Wisconsin Schizotypy Scales across 


\section{Author's Pre-print}

Gender and Age. The Spanish Journal of Psychology, 13(02), 941-950.

http://doi.org/10.1017/S1138741600002584

Fonseca-Pedrero, E., Paino, M., Ortuño-Sierra, J., Lemos-Giráldez, S., \& Muñiz, J. (2014).

The assessment of positive dimension of the psychosis phenotype in college students.

Comprehensive Psychiatry, 55(3), 699-707. http://doi.org/10.1016/j.comppsych.2013.09.013

Frith, C. D. (2008). The cognitive neuropsychology of schizophrenia. London: Routledge.

Garety, P. A., Hemsley, D. R., \& Wessely, S. (1991). Reasoning in deluded schizophrenic and paranoid patients: biases in performance on a probabilistic inference task. Journal of Nervous and Mental Disease, 179(4), 194-201.

Gooding, D. C., Tallent, K. A., \& Matts, C. W. (2007). Rates of avoidant, schizotypal, schizoid and paranoid personality disorders in psychometric high-risk groups at 5-year follow-up. Schizophrenia Research, 94(1-3), 373-374.

http://doi.org/10.1016/j.schres.2007.04.018

Granger, K. T., Prados, J., \& Young, A. M. J. (2012). Disruption of overshadowing and latent inhibition in high schizotypy individuals. Behavioural Brain Research, 233(1), 201-208. http://doi.org/10.1016/j.bbr.2012.05.003

Grant, P., Balser, M., Munk, A.J.L., Linder, J. \& Hennig, J. (2014). A false-positive detection bias as a function of state and trait schizotypy in interaction with intelligence. Frontiers in Psychiatry 5:135. http://doi.org/10.3389/fpsyt.2014.00135 
Author's Pre-print

Gray, N. S., Fernandez, M., Williams, J., Ruddle, R. A., \& Snowden, R. J. (2002). Which schizotypal dimensions abolish latent inhibition? The British Journal of Clinical Psychology / the British Psychological Society, 41(Pt 3), 271-284.

Hoshi, R., Scoales, M., Mason, O., \& Kamboj, S. K. (2011). Schizotypy and emotional memory. Journal of Behavior Therapy and Experimental Psychiatry, 42(4), 504-510. http://doi.org/10.1016/j.jbtep.2011.05.003

Huq, S. F., Garety, P. A., \& Hemsley, D. R. (1988). Probabilistic judgements in deluded and non-deluded subjects. The Quarterly Journal of Experimental Psychology Section A, 40(4), 801-812. http://doi.org/10.1080/14640748808402300

Kaymaz, N., Drukker, M., Lieb, R., Wittchen, H.-U., Werbeloff, N., Weiser, M., Lataster, T., \& van Os, J. (2012). Do subthreshold psychotic experiences predict clinical outcomes in unselected non-help-seeking population-based samples? A systematic review and metaanalysis, enriched with new results. Psychological Medicine, 42(11), 2239-2253. http://doi.org/10.1017/S0033291711002911

Kumari, V., Soni, W., Mathew, V. M., \& Sharma, T. (2000). Prepulse inhibition of the startle response in men with schizophrenia: effects of age of onset of illness, symptoms, and medication. Archives of General Psychiatry, 57(6), 609-614. 


\section{Author's Pre-print}

Launay, G., \& Slade, P. (1981). The measurement of hallucinatory predisposition in male and female prisoners. Personality and Individual Differences, 2(3), 221-234.

http://doi.org/10.1016/0191-8869(81)90027-1

Levine, E. (2004). Interpersonal attributional biases in hallucinatory-prone individuals. Schizophrenia Research, 69(1), 23-28. http://doi.org/10.1016/S0920-9964(02)00493-0

Levitan, C., Ward, P. B., Catts, S. V., \& Hemsley, D. R. (1996). Predisposition toward auditory hallucinations: the utility of the Launay-Slade Hallucination Scale in psychiatric patients. Personality and Individual Differences, 21(2), 287-289. http://doi.org/10.1016/0191-8869(96)00052-9

Mason, O., Claridge, G., \& Jackson, M. (1995). New scales for the assessment of schizotypy. Personality and Individual Differences, 18(1), 7-13. http://doi.org/10.1016/0191$\underline{8869(94) 00132-\mathrm{C}}$

Nettle, D. (2006). Schizotypy and mental health amongst poets, visual artists, and mathematicians. Journal of Research in Personality, 40(6), 876-890.

http://doi.org/10.1016/j.jrp.2005.09.004

Park, H. R. P., Kirk, I. J., \& Waldie, K. E. (2015). Neural correlates of creative thinking and schizotypy. Neuropsychologia, 73, 94-107.

http://doi.org/10.1016/j.neuropsychologia.2015.05.007 


\section{Author's Pre-print}

Preti, A., Bonventre, E., Ledda, V., Petretto, D. R., \& Masala, C. (2007). Hallucinatory Experiences, Delusional Thought Proneness, and Psychological Distress in a Nonclinical Population: The Journal of Nervous and Mental Disease, 195(6), 484-491. http://doi.org/10.1097/NMD.0b013e31802f205e

Preti, A., Sisti, D., Rocchi, M. B. L., Siddi, S., Cella, M., Masala, C., Pettreto, D. R., \& Carta, M. G. (2014). Prevalence and dimensionality of hallucination-like experiences in young adults. Comprehensive Psychiatry, 55(4), 826-836.

http://doi.org/10.1016/j.comppsych.2014.01.015

Rawlings, D., \& Locarnini, A. (2008). Dimensional schizotypy, autism, and unusual word associations in artists and scientists. Journal of Research in Personality, 42(2), 465-471. http://doi.org/10.1016/j.jrp.2007.06.005

Schultze-Lutter, F., Fluckiger, R., Michel, C., \& Hubl, D. (2018). Schizotypy in Patients from a Clinical High Risk Service: Trait or State? Schizophrenia Bulletin, 44(Supplement 1), 407408. https://doi.org/10.1093/schbul/sby018.998

Stefanis, N. C., Vitoratou, S., Ntzoufras, I., Smyrnis, N., Evdokimidis, I., \& Stefanis, C. N. (2006). Psychometric properties of the Greek version of the Schizotypal Personality Questionnaire (SPQ) in young male obligatory conscripts: A two years test-retest study. Personality and Individual Differences, 41(7), 1275-1286.

http://doi.org/10.1016/j.paid.2006.07.003 


\section{Author's Pre-print}

Shrira A., \& Tsakanikos, E. (2009). Latent inhibition as a function of schizotypal symptoms: evidence for a bi-directional model. Personality and Individual Differences, 47(5), 922-927. http://dx.doi.org/10.1016/j.paid.2009.04.015

Tsakanikos, E. (2006). Perceptual biases and positive schizotypy: The role of perceptual load. Personality and Individual Differences, 41(5), 951-958.

http://doi.org/10.1016/j.paid.2006.04.004

Tsakanikos, E., \& Claridge, G. (2005). More words, less words: Verbal fluency as a function of "positive" and "negative" schizotypy. Personality and Individual Differences, 39(4), 705713. http://doi.org/10.1016/j.paid.2005.02.019

Tsakanikos, E., \& Reed, P. (2005a). Dimensional approaches to experimental psychopathology of schizophrenia: shift learning and report of psychotic-like experiences in college students. Journal of Behavior Therapy and Experimental Psychiatry, 36(4), 300-312. http://doi.org/10.1016/j.jbtep.2004.10.002

Tsakanikos, E., \& Reed, P. (2005b). Do Positive Schizotypal Symptoms Predict False Perceptual Experiences in Nonclinical Populations?: The Journal of Nervous and Mental Disease, 193(12), 809-812. http://doi.org/10.1097/01.nmd.0000188974.44468.92

Tsakanikos, E., \& Reed, P. (2005c). Seeing words that are not there: Detection biases in schizotypy. British Journal of Clinical Psychology, 44(2), 295-299.

http://doi.org/10.1348/014466505X28757 


\section{Author's Pre-print}

Van Wout, M., Aleman, A., Kessels, R., Laroi, F., \& Kahn, R. (2004). Emotional processing in a non-clinical psychosis-prone sample. Schizophrenia Research, 68(2-3), 271-281. http://doi.org/10.1016/j.schres.2003.09.006

Vellante, M., Larøi, F., Cella, M., Raballo, A., Petretto, D. R., \& Preti, A. (2012).

Hallucination-Like Experiences in the Nonclinical Population: The Journal of Nervous and Mental Disease, 200(4), 310-315. http://doi.org/10.1097/NMD.0b013e31824cb2ba

Woodward, T. S., Buchy, L., Moritz, S., \& Liotti, M. (2007). A Bias Against

Disconfirmatory Evidence Is Associated With Delusion Proneness in a Nonclinical Sample. Schizophrenia Bulletin, 33(4), 1023-1028. http://doi.org/10.1093/schbul/sbm013

Woodward, T. S., Moritz, S., Cuttler, C., \& Whitman, J. C. (2006). The contribution of a cognitive bias against disconfirmatory evidence (BADE) to delusions in schizophrenia. Journal of Clinical and Experimental Neuropsychology, 28(4), 605-617. http://doi.org/10.1080/13803390590949511

Yeon Jung, H., Seung Chang, J., Seo Yi, J., Hwang, S., Shin, H.-K., Hoon Kim, J., \& Sik Kim, Y. (2008). Measuring psychosis proneness in a nonclinical Korean population: is the Peters et al Delusions Inventory useful for assessing high-risk individuals? Comprehensive Psychiatry, 49(2), 202-210. http://doi.org/10.1016/j.comppsych.2007.08.011 
Table 1

Correlations between age and scale measures $(n=804)$

\begin{tabular}{ccccc}
\hline & UE & UE1 & UE2 & UE3 \\
\hline Age & $-.08^{*}$ & -.05 & $-.11^{* *}$ & -.07
\end{tabular}

* Correlation is significant at the .05 level (2-tailed).

** Correlation is significant at the .01 level (2-tailed).

Abbreviations: UnEx O-LIFE Oxford-Liverpool Inventory of Feelings and Experiences, UE1 -3 Unusual Experiences Subscale $1-3$

Table 2

Group statistics according to $\operatorname{sex}(n=805)$

\begin{tabular}{|c|c|c|c|c|}
\hline & Sex & $\mathrm{N}$ & Mean & S.D \\
\hline \multirow[t]{2}{*}{ UE } & Male & 300 & 10.02 & 6.24 \\
\hline & Female & 505 & 10.17 & 6.12 \\
\hline \multirow[t]{2}{*}{ UE1 } & Male & 300 & 2.21 & 2.09 \\
\hline & Female & 505 & 2.25 & 2.09 \\
\hline \multirow[t]{2}{*}{ UE2 } & Male & 300 & 3.67 & 2.31 \\
\hline & Female & 505 & 3.79 & 2.17 \\
\hline \multirow[t]{2}{*}{ UE3 } & Male & 300 & 2.11 & 1.82 \\
\hline & female & 505 & 2.05 & 1.75 \\
\hline
\end{tabular}


Author's Pre-print

Table 3

Correlations between UE and related measures $(n=108)$

\begin{tabular}{|c|c|c|c|c|c|c|}
\hline & UE & UE1 & UE2 & UE3 & ASI & LSHS \\
\hline UE1 & $.81^{* *}$ & & & & & \\
\hline UE2 & $.85^{* *}$ & $.54 * *$ & & & & \\
\hline UE3 & $.73 * *$ & $.45^{* *}$ & $.51 * *$ & & & \\
\hline ASI & $.68 * *$ & $.47 * *$ & $.62 * *$ & $.46 * *$ & & \\
\hline LSHS & $.75^{* *}$ & $.67 * *$ & $.72 * *$ & $.39 * *$ & $.51 * *$ & \\
\hline MIS & $.69 * *$ & $.48^{* *}$ & $.47 * *$ & $.70 * *$ & $.57 * *$ & $.35^{* *}$ \\
\hline
\end{tabular}

**Correlation is significant at the .01 level (2-tailed).

Abbreviations: UE Unusual Experiences scale, UE1 -3 Unusual Experiences Subscales 1 - 3, ASI Aberrant Salience Inventory, LSHS Launay-Slade Hallucination Scale, MIS Magical Ideation Scale 
Table 4

Correlations between Unusual Experiences Scales and Coping Mechanisms $(n=108)$

\begin{tabular}{|c|c|c|c|c|c|c|c|}
\hline & UnEx & UE1 & UE2 & UE3 & ASI & LSHS & MIS \\
\hline $\mathrm{CC}$ & .17 & -.06 & $.24 *$ & .18 & $.33 * *$ & .13 & .13 \\
\hline Dist & .16 & .11 & .14 & .07 & .19 & $.28 * *$ & -.07 \\
\hline SC & $.20 *$ & .13 & $.23 *$ & .09 & $.25^{*}$ & $.35^{* *}$ & -.03 \\
\hline SSS & .07 & -.09 & .18 & .14 & .16 & .06 & .11 \\
\hline $\mathrm{AR}$ & $.20 *$ & .05 & $.29 * *$ & .12 & $.23 *$ & $.24 *$ & -.01 \\
\hline EA & $.37 * *$ & .17 & $.40 * *$ & $.27 * *$ & $.36 * *$ & $.34 * *$ & .18 \\
\hline PPS & .05 & .02 & .08 & .04 & .09 & .17 & .03 \\
\hline PR & .10 & -.08 & .12 & .13 & $.32 * *$ & .10 & .19 \\
\hline
\end{tabular}

**Correlation is significant at the .01 level (2-tailed).

* Correlation is significant at the .05 level (2-tailed).

Abbreviations: O-LIFE Oxford-Liverpool Inventory of Feelings and Experiences (Unusual Experiences Portion), UE1 -3 Unusual Experiences Subscale 1 - 3, ASI Aberrant Salience Inventory, LSHS Launay-Slade Hallucination Scale, MIS Magical Ideation Scale, CC - Confrontive Coping, Dist - Distancing, SC - Self-Controlling, SSS - Seeking social support, AR-Accepting responsibility, EA - Escape-Avoidance, PPS - Planful problem solving, PR-Positive Re-appraisal 
Figure 1

Model Fit for UE sub-scales of O-LIFE $(n=829)$

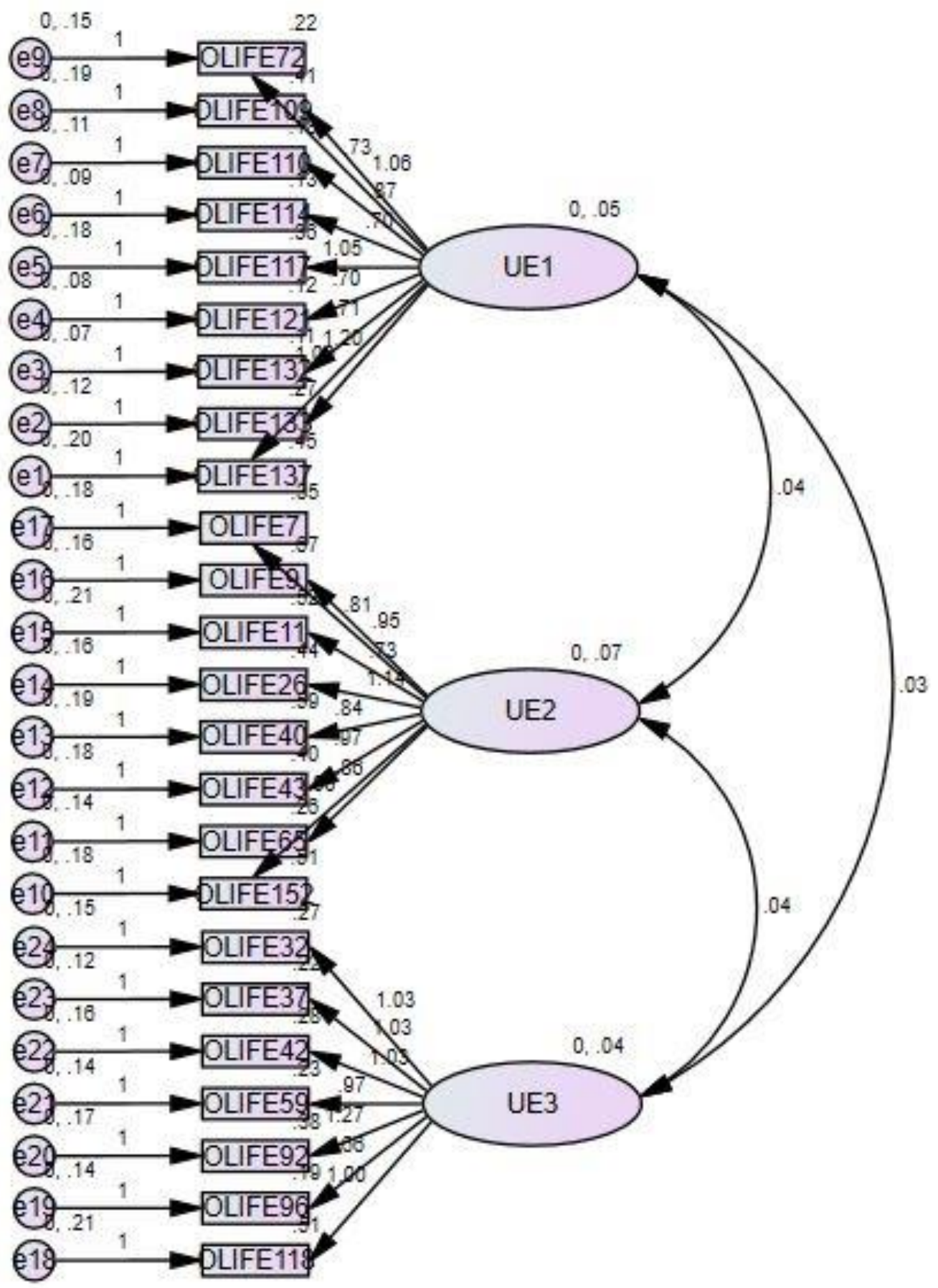


Author's Pre-print

Figure 2

Illustration of non-constrained model fit for UE sub-scales of the O-LIFE $(n=829)$

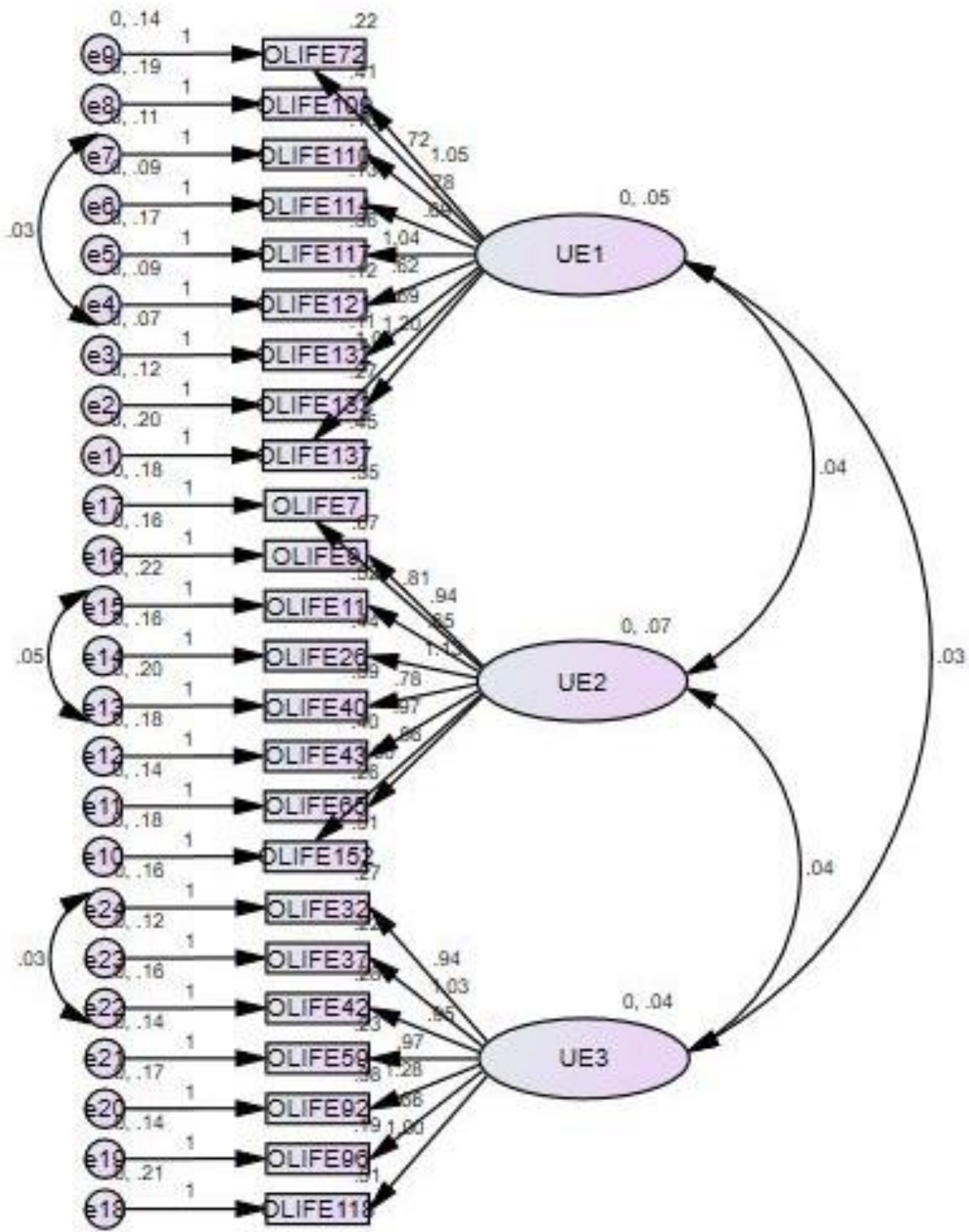




\section{Appendix 1}

\section{UE1 - Unusual perceptions}

Is your hearing sometimes so sensitive that ordinary sounds become uncomfortable?

Have you ever thought you heard people talking only to discover that it was in fact a nondescript noise?

Have you occasionally felt that your body does not exist?

On occasions, have you seen a person's face in front of you when no one was in fact there?

Do you often have a day when indoors lights seem so bright that they bother your eyes?

Have you felt as though your head or limbs were somehow not your own?

Do you ever feel that your thoughts don't belong to you?

Do you ever feel suddenly distracted by distant sounds that you are not normally aware of?

When in dark, do you often see forms and shapes even though there is nothing there?

\section{UE2 - Unusual salience /reality monitoring}

Are the sounds you hear in your daydreams usually clear and distinct?

Do your thoughts sometimes seem as real as actual events in your life?

Does it often happen that nearly every thought immediately and automatically suggests an enormous number of ideas? 


\section{Author's Pre-print}

Are your thoughts sometimes so strong that you can almost hear them?

Do ideas and insights sometimes come to you so fast that you cannot express them all?

Does a passing thought sometimes seem so real that it frightens you?

Do people in your daydreams sometimes seem so true to life that you sometimes think they are real?

Do you ever feel sure that something is about to happen, even though there does not seen to be any reason for you thinking that?

\section{UE3 Unusual thoughts}

Do you think that you could learn to read other's minds if you wanted to?

Have you ever felt that you have special, almost magical powers?

Can some people make you aware of them just by thinking about you?

Do you sometimes feel that your accidents are caused by mysterious forces?

Have you felt that you might cause something to happen just by thinking too much about it?

Do you feel so good at controlling others that it sometimes scares you?

Have you wondered whether the spirits of dead can influence the living? 
Author's Pre-print

\section{Acknowledgements}

This research research was part of a $\mathrm{PhD}$ thesis funded by the Department of Psychology, University of Roehampton. The authors wish to thank Professor Paul Allen and Professor Philip Corr for their helpful comments and suggestions on an earlier version of this report. Thanks also due to two anonymous reviewers for the constructive comments. 